\title{
Carta das mulheres para a cidade de Blumenau: percepções, demandas e reflexões sobre o direito das mulheres à cidade
}

\author{
Women's Charter for the city of Blumenau: perceptions, demands \\ and reflections on women's right to the city
}

\author{
Daniela Pareja Garcia Sarmento ${ }^{1}$
}

Fecha de recepción: 04-04-2018 - Fecha de aceptación: 30-07-2018

Hábitat y Sociedad (ISSN 2173-125X), n. ${ }^{\circ} 11$, noviembre de 2018, pp. 85-107.

http://dx.doi.org/10.12795/HabitatySociedad.2018.i11.06

\begin{abstract}
It aims to discuss the women's right to the city, due to gender inequality related to the access and the use of urban infrastructure in the city of Blumenau, in the south of Brazil. This article makes a review of the research entitled "The participation of women in the construction of the contemporary city: contributions to a new model of urban planning in Blumenau" presented in the Master Program in Regional Development of Fundação Universidade Regional de Blumenau (FURB). The article presents some practical results achieved during the research. One of them are the meetings with the groups of women, which enabled the organization of a document named "Carta das Mulheres para a Cidade de Blumenau", that systematizes the demands raised by them during the discussions. This document was layed at the 6th Conference of the City of Blumenau, held in June 2016, and was also sent to be part of the revision process of the city Master Plan. The process of discussion and construction of this research made possible an approach with the reality of women, contributing as a theoretical support to the dialogues and experiences on the use of the city and to the understanding of their right to the city. The survey's conclusion points out the relevance of the discussion about the gender issue in the elaboration of urban public policies, once that women use the city in a differentiated way. Thus, when thinking about the city of Blumenau in the perspective of women, it opens the way to the humanization of the urban planning process.
\end{abstract}

Key words

Women; Gender Urbanism; Citizen Participation; Right to the City

\section{Resumo}

Objetiva discutir o direito das mulheres à cidade, frente à desigualdade de gênero em relação ao acesso e ao uso da infraestrutura urbana na cidade de Blumenau, no sul do Brasil. Este artigo traz um recorte da pesquisa "A participação da mulher na construção da cidade contemporânea: contribuições para um novo modelo de planejamento urbano em Blumenau" desenvolvida para o Programa de Mestrado em Desenvolvimento Regional da Fundação Universidade Regional de Blumenau (FURB). O estudo traz alguns resultados práticos alcançados ao longo da pesquisa, onde os encontros com as mulheres possibilitaram a organização de um documento que sistematizou as demandas levantadas por elas ao longo das discussões, o que resultou na construção do documento "Carta das Mulheres para a Cidade de Blumenau", protocolado na $6^{\text {a }}$ Conferência da Cidade de Blumenau, realizada em junho de 2016, e que foi encaminhado para processo de revisão do Plano Diretor da cidade de Blumenau. Esse processo de discussão e construção da pesquisa possibilitou um encontro direto com a realidade das mulheres, contribuindo como amparo teórico para os diálogos e trocas de experiências sobre o uso da cidade, onde foi possível identificar suas demandas e sua compreensão sobre o direito à cidade. A conclusão aponta para a relevância da discussão sobre a questão de gênero na elaboração de políticas públicas urbanas, pois se verificou que as mulheres utilizam a cidade de forma diferenciada. Assim, ao pensar a cidade de Blumenau na perspectiva das mulheres, abre-se caminho para a humanização do processo de planejamento urbano.

\section{Pallavras chave}

Mulheres; Urbanismo de Gênero; Participação Cidadã; Direito à Cidade

1 Mestre em Desenvolvimento Regional (FURB); professora do curso de Graduação em Arquitetura e Urbanismo da Universidade Regional de Blumenau, FURB, Brasil; arquiteta no Estúdio Terra Arquitetura \& Planejamento. E-mail: daniela@terra.arq.br. 


\section{Introdução}

Ao distinguir as influências das esferas públicas e privadas, e compreendendo as diferenças entre as relações sociais entre homens e mulheres, onde o mundo público —econômico e político—cabe aos homens, e o mundo privado -íntimo e doméstico- cabe às mulheres, podemos dizer que a cidade é sexuada.

Em função dessa divisão Calió (1991) chama atenção para a "invisibilização" das mulheres na multidão urbana. "Elas estão lá, importantes para o cenário, mas insignificantes para a cena” (p. 4). É com essa provocação que iniciamos a reflexão sobre o direito da mulher à cidade e à cidadania, buscando compreender as bases dessa invisibilidade e como isso afeta o cotidiano das mulheres e seu direito à cidade. Outra questão que se coloca para o debate é a suposta neutralidade do espaço urbano tendo como pressuposto o atendimento a um sujeito universal. Assim, havendo um sujeito universal, mascarado como sendo do sexo masculino, porém abrangendo genericamente homens e mulheres, a cidade atenderia as especificidades da vida cotidiana de todos? Muxí (2012) defende que a universalidade esconde o verdadeiro sujeito de direito, uma vez que o universalismo tem como critério desenvolver-se como referência do mundo público, com a participação no mercado e os espaços atribuídos aos homens, e não inclui espaço doméstico -definido como feminino e onde as atividades da função reprodutiva acontecem. Desta forma, defende que essa neutralidade é falsa.

Assim, cabe entender, a partir da necessidade e do direito de todos, para quem a cidade é pensada, buscando compreender a diversidade e as especificidades que existem entre homens e mulheres ao utilizar a cidade, ao desenvolverem suas atividades produtivas e reprodutivas. Esse fato aponta para a importância de conhecer suas distintas experiências ao planejar espaços públicos para garantir acesso igualitário à cidade e à cidadania.

A inserção da mulher no meio urbano pode ser considerada um avanço pela conquista por mais espaço e inserção no fluxo produtivo da sociedade contemporânea. Uma vez que a história das mulheres deixa clara a luta constante pelo direito à emancipação política e pelo direito à cidadania.

Nesse sentido, cabe compreender esse cenário considerando a realidade brasileira, que hoje, é uma das dez maiores economias do mundo e, ao mesmo tempo, um dos quatro países do mundo com maior concentração de riqueza e desigualdade social. Essa desigualdade atinge em especial às mulheres, que são a maioria da população brasileira, mais pobres que os homens, ganham menores salários e assumem maiores responsabilidades, acumulando as tarefas do trabalho com os cuidados familiares e os afazeres domésticos.

A Organização das Nações Unidas (ONU) traz a informação de que a cada 100 proprietários, apenas um é mulher. No universo financeiro, a Organização Internacional do Trabalho (OIT), órgão da ONU, relata que as mulheres exercem três quartos do trabalho e da produção de riquezas no mundo e recebem apenas a quarta parte. No Brasil, as mulheres recebem $70 \%$ dos salários ganhos pelos homens, tendo quase o dobro do nível de escolaridade (Gonzaga, 2004). Esses dados demonstram a desigualdade em que vivem as mulheres e, com isso, faz sentido seu destaque na luta pela universalização dos direitos sociais, civis e políticos.

A discussão e luta pela inclusão das demandas das mulheres não é recente e vários autores reclamam e abordam essa temática com a fi- 
nalidade de contribuir com a reflexão acerca das transformações urbanísticas. São vários aqueles que buscam na história da evolução urbana e do espaço público refletir sobre a contribuição da mulher na formação das cidades, no processo de urbanização e industrialização (Santoro, 2008).

Num breve resgate sobre a participação da mulher na construção da cidade e pela luta de seus direitos e cidadania, cabe ressaltar que, historicamente, muitos movimentos de bairros, comunitários e de saúde, têm sua base na organização feminina.

O fato é que as mulheres estão inseridas na luta pelas cidades, porém diversos trabalhos enfatizam que as mulheres ainda ocupam uma posição secundária nesta questão. Desta forma, buscou-se nesta pesquisa uma reflexão crítica acerca da prática da arquitetura e do urbanismo na construção do modelo atual de cidade e sua capacidade de incluir a todos. Atualmente a estrutura urbana se mantém e se transforma com prioridade para atender a demanda do capital e as prioridades masculinas, considerando que a cidade é desenhada para atender o fluxo dos homens, em idade média, no auge de sua capacidade produtiva, com trabalho estável e bem remunerado que lhe permite ter carro, deixando as demandas das mulheres, jovens, idosos, crianças e deficientes físicos à margem das prioridades do investimento público. Essa lógica de desenvolvimento excludente pautou o desenho das cidades ao longo dos séculos XIX e Xx (Montaner y Muxí, 2014).

Diante dessa problemática levantada, uma hipótese pode ser iniciada fazendo uma analogia entre a maneira pela qual o espaço urbano foi construído e o modo pelo qual o papel da mulher foi estruturado. Ao considerar que em ambos os casos, o que foi construído pode ser desconstruído, é possível pensar que a invisibilidade histórica que envolveu a participação da mulher na construção do território pode ser revisada, permitindo que se lance uma nova construção, pautada na visibilidade e protagonismo da mulher em defesa de suas demandas na cidade.

Trata-se de um modelo de desenvolvimento que precisa ser revisto, considerando os dados levantados em 2010 pelo Instituto Brasileiro de Geografia e Estatísticas (IBGE) onde este aponta que a população brasileira se constitui em sua maioria de mulheres. Outro dado importante é o aumento de $38,6 \%$ de famílias que possuem a mulher como responsável pelo seu provento. Esse número se altera para 39,3\% quando as famílias vivem em área urbana e diminui para 24,8\% para famílias que vivem em área rural. Diante desses fatos, percebe-se como o papel da mulher se altera diante das mudanças de representatividade social e influência econômica.

Neste contexto, cabe compreender o papel do Estado democrático como referência principal para atender as demandas sociais, e traz um alerta sobre a nova ordem econômica mundial pela invasão do pensamento neoliberal e pela redução do Estado. Dessa forma, a tensão aumenta e piora a condição da mulher, uma vez que as mulheres acumulam a segregação de classe social e a segregação por sexo. Diante deste fato, reforça-se a necessidade de tomada de consciência desta vulnerabilidade e a importância de se organizar, enquanto força política, para ter condições de ocupar espaços políticos e participar da gestão das cidades, pois trata-se de um direito garantido pelo Estatuto da Cidade assim como pelos organismos de políticas públicas para as mulheres.

A busca por alternativas para o desenvolvimento urbano e novos modos de usar e participar da cidade é o desafio que se coloca, pois 
mesmo com o Estatuto da Cidade ${ }^{2}$ são poucos os municípios que conseguiram incluir de forma estratégica a questão de gênero em suas políticas urbanas, já que a maioria dos municípios brasileiros ainda tem suas políticas urbanas como uma representação ideológica que não reflete a demanda da cidade real, sua diversidade de classes sociais, gênero, cores, faixas etárias, orientação sexual e deficiência física. Um exemplo são os planos diretores, cuja maioria se atém às dimensões estruturais, deixando de apontar propostas de ação, políticas setoriais e transversais que venham melhorar o habitat, assim como o desenvolvimento social e econômico (Gonzaga, 2004).

Diante desta realidade, o trabalho traz como tema o desenvolvimento urbano pautado na experiência, percepção e demandas das mulheres na cidade de Blumenau para compreender a necessidade de um novo modelo de desenvolvimento urbano inclusivo e para todos. Cabe aqui localizar Blumenau como uma cidade de médio porte, com aproximadamente trezentos mil habitantes, que integra a região metropolitana do Vale do Itajaí e está situada em Santa Catarina, ao sul do Brasil.

Para a realização desta pesquisa, a seguinte pergunta norteou o trabalho: Atualmente, quais são as demandas e percepções acerca da cidade de Blumenau pela ótica da mulher?

Como objetivo, buscou-se identificar e promover uma reflexão sobre a inclusão das necessidades das mulheres na pauta de discussão sobre o desenvolvimento urbano de Blumenau, além de debater as possibilidades de construção de uma nova cultura para o habitar na cidade contemporânea.

No desenvolvimento desta pesquisa foram articulados conhecimentos multidisciplinares, tendo como enfoque a participação e interação das mulheres com suas experiências no cotidiano da cidade, considerando a vida doméstica, trabalho, lazer, relações públicas e privadas, para promover uma análise da dimensão humana no território.

\section{A perspectiva da mulher no contexto do planejamento urbano}

A inserção da mulher no meio urbano pode ser considerada um avanço pela conquista por mais espaço e inserção no fluxo produtivo da sociedade contemporânea. A história das mulheres deixa clara a luta constante pelo direito à emancipação política e pelo direito à cidadania. Porém, essa inserção ainda se dá de forma desigual em pleno século xxi para a maioria das mulheres, uma vez que as cidades se desenvolveram sem a participação das mesmas no debate das políticas públicas e urbanas.

Assim, cabe trazer o universo da mulher ao analisar a abordagem de gênero na história, para compreender as transformações ocorridas por um conjunto de fatores que tem dado visibilidade à mulher, como a ampliação de acesso ao mercado de trabalho, acesso às universidades, lutas pelos direitos, liberdade e conquista pelo espaço público.

Neste sentido, é preciso compreender o papel da mulher como agente de mudança e como se deu a sua inserção no espaço da cidade. Necessário, então, contextualizar que esse processo inicia-se de forma desigual em relação ao homem, uma vez que no processo de construção das classes sociais e das relações de gênero, no caso da mulher, a primeira opressão se deu pelo homem que, para garantir sua propriedade, colocou a mulher e seus filhos em condição de subserviência, res-

2 Texto completo com as diretrizes urbanas prevista na Lei do Estatuto da Cidade encontra-se disponível em: http:// www.planalto.gov.br/ccivil_03/leis/ LEIS_2001/L10257.htm. Acesso em 24 out. 2015 . tringindo a mulher ao espaço privado. 
Historicamente, essa condição de desigualdade de direito e acesso à cidadania marcou a luta pela emancipação das mulheres. No caso da relação das mulheres com a cidade, não há como compreender sem considerar a relação de classe e de propriedade, como defende o filósofo Henri Lefébvre (1969). Desta forma, Gonzaga (2004) conclui que o direito a cidade foi negado à mulher diante da condição de ser historicamente pertencente a classes inferiores e sem posses.

Essa relação se deu além das regras impostas pelas instituições e foi uma questão cultural que sustentou uma ideologia dominante patriarcal, onde se desenvolveu um arcabouço de justificativas para embasar o caráter inferior da mulher e posicioná-la na condição de procriadora. Essa condição limitou a emancipação da mulher, restringindo seu papel às questões domésticas, familiares e de forma subalterna, sem direito à propriedade, sem direito a defender seu próprio corpo e sem acesso à cidadania.

Essas transformações contribuíram para o surgimento dos conflitos espaciais, na forma de usar a cidade, na decisão de divisão de tempo entre homens e mulheres em sua relação trabalho e família, acesso à mobilidade, segurança, infraestrutura de apoio aos filhos, saúde e lazer. Assim, a cidade passou a ser reivindicada para atender uma nova dinâmica de funcionamento e de prioridades. Essa é uma questão chave dessa reflexão, quando a mulher acessa o mercado de trabalho e a cidade transforma-se em suporte para tarefas do cotidiano da família, como trabalhar, morar, circular, estudar e se divertir. Diante deste contexto, Montaner (2012) traz as seguintes questões: qual é a prioridade que se dá para atender a demanda da mulher?, para quem a cidade é pensada?

Calió (1991) complementa essa questão retomando o papel do gênero como abordagem estratégica para diminuição da desigualdade, e traz a discussão sobre a divisão de poder e sua influência nos papéis que homens e mulheres desempenham na sociedade.

Visto como categoria analítica da realidade social, o gênero traz visibilidade às mulheres e permite outras re-leituras dos fenômenos sociais. Assumir a categoria de gênero significa identificá-lo a partir dos vários espaços onde ele se constrói: na cidade, na família, no mercado de trabalho, nas instituições, na subjetividade... Significa também trazer à tona a relação de gênero como relação de poder —uma relação impossível de ser explicada pela biologia da mesma forma que a dominação racial- A sociedade deve estar preocupada não só com as desigualdades sócio-espaciais, fruto das diferenças sociais, mas também com as relações de poder entre os gêneros, ou seja, as relações sociais entre os sexos em relação à evolução do espaço rural e urbano (Calió, 1991, p. 1).

Lançar o olhar diante dessa evolução significa trazer luz ao urbanismo a partir de uma perspectiva de gênero e perceber as lacunas que se encontram em aberto atrás do pensamento universal. Uma delas é a importância de considerar os diferentes papéis, particularidades e necessidades que homens e mulheres desempenham ao desenvolver suas vidas na cidade. Reconhecendo essas particularidades, é possível propor soluções e políticas públicas que permitam acesso mais igualitário às oportunidades.

A perspectiva de gênero aplicado ao urbanismo significa colocar iguais condições às exigências decorrentes do mundo produtivo e derivado mun- 
do reprodutiva, ou seja, o cuidado diário que as pessoas precisam. Os dois mundos têm que estar ao mesmo nível de importância decisões para evitar a expansão ou a manutenção de diferenças (Muxí, Casanovas, Ciocoletto et al., 2011, p. 12).

Assim, Muxí (2012) defende que a cidade pensada na perspectiva de gênero precisa garantir a mistura, o acesso e a sobreposição das funções para facilitar o desenvolvimento da vida cotidiana, considerando a diversidade de usuários e a diversidade de momentos de utilização. Desta forma a perspectiva de gênero aplicado ao urbanismo é entendida pela experiência e, portanto, pressupõe uma atuação mais próxima e conectada com o usuário -mas isto não exclui o plano geral com sua função analítica norteadora.

Além de compreender a dimensão metodológica do urbanismo de gênero, cabe discutir sua demanda política como sendo um modelo pautado na participação e divisão de poder. Nesse sentido, é importante ressaltar o que recomenda o documento desenvolvido pelo Instituto Brasileiro de Administração Municipal (IBAM) no livro Introdução ao Planejamento para o Gênero: um guia prático:

O processo de desenvolvimento exige a participação de todos, e a todos deve beneficiar. Por isso, os governantes devem buscar minimizar todas as formas de discriminação presentes na sociedade, combatendo qualquer distribuição injusta de direitos e buscando um desenvolvimento sempre mais igualitário. A desigualdade de gênero deve ser reconhecida. O planejamento que leva em conta as características específicas de homens e mulheres -ou seja, o planejamento que incorpora a perspectiva de gênero- é um instrumento para isso (Costa, 1997, p. 12).

Cabe ressaltar ainda que, ao discutir o urbanismo com perspectiva de gênero, não significa forçar uma narrativa de vitimização da mulher e nem tão pouco construir uma cultura feminina perdendo-se em uma mera perspectiva essencialista. Ao tornar visível a condição e a contribuição da mulher para o desenvolvimento das cidades, abre-se a possibilidade de revisitar a experiência coletiva de homens e mulheres na cidade, bem como buscar metodologias que permitam um aprimoramento das relações sociais entre os sexos e, assim, valorizar e integrar suas contribuições, cada qual com seu processo histórico e de identidade.

Assim, ao estudar o universo das mulheres relacionando sua condição com espaço e tempo, ampliam-se as possibilidades de investigação e renovam-se metodologias de marcos conceituais tradicionais, buscando relacionar, a partir do âmbito cotidiano e não apenas na esfera política, as transformações da sociedade e tecendo um olhar sob a influência da mulher no ambiente privado, como funcionamento da família, a luta pela emancipação e gestos cotidianos. Desta forma, ao relacionar o urbanismo à luz da perspectiva de gênero, deslocamos o enfoque das transformações que ocorrem no território, pautadas pelo campo de poder das Instituições e do Estado, e passamos a observar as transformações que ocorrem na esfera do privado e do cotidiano, buscando compreender as contribuições do universo da mulher na cidade. 


\section{A mulher e suas percepções, demandas e reflexões sobre a cidade}

Trata-se de uma pesquisa qualitativa feita com o intuito de conhecer o funcionamento dos lugares da cidade que trazem uma compreensão do espaço urbano através da perspectiva das mulheres. Marta Román (2008) afirma que a participação cidadã pode ser incorporada como ferramenta no processo de planejamento urbano e cita como referência os Ateliês do Futuro, EASW (European Awareness Scenario Workshop), mesas de planos, dentre outras metodologias. Para o sucesso dessas metodologias, a autora sugere o envolvimento de uma ampla diversidade cultural dos participantes, para se obter informações que possam demonstrar as diversas percepções do modo de viver, aprender, construir e interagir nos espaços da cidade (Román y Velázquez, 2008).

A opção pela pesquisa qualitativa se dá porque ela permite incorporar os significados e intencionalidades do sujeito relacionado aos seus atos, às suas relações e às estruturas sociais que são adotadas tanto no seu universo particular quanto na sua capacidade de transformação como construções humanas (Minayo, 2007). Nessa perspectiva, a pesquisa aplicada esteve pautada na subjetividade, na experiência, no afeto e nas relações cotidianas dessas mulheres com Blumenau. As etapas da pesquisa foram divididas em três exercícios a saber: bibliográfico, documental e diagnóstico participativo.

A fase para promover o diagnóstico participativo através de diálogos e interação entre as mulheres que participaram da pesquisa teve como suporte teórico o método desenvolvido pelo grupo ColletiuPunt6, coordenado pela Arquiteta e Urbanista feminista Zaida Muxí, professora da Universidade de Barcelona, utilizando como base o livro "Espacios para la vida cotidiana: auditoria de calidad urbana com

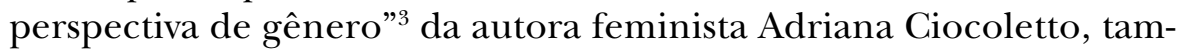
bém integrante do coletivo Col.lectiu Punt 6. Essa metodologia se posiciona com base no pensamento feminista, o que permitiu perceber a aplicação transversal da perspectiva de gênero nas análises urbanas, tanto para detectar o funcionamento e eficiência do espaço como para sua aplicação como estratégia de gestão urbana e definição de políticas públicas. Feitas as análises que integram os aspectos sociais, físicos e funcionais foi possível identificar as principais demandas e expectativas pautadas na experiência coletiva entre diversas mulheres que participaram da pesquisa.

A pesquisa foi estruturada com a participação de dois grupos de mulheres, moradoras de Blumenau, com realidades socioeconômicas e vivências espaciais distintas. Desta forma, foram realizados encontros com moradoras de bairros periféricos da cidade, incluindo os condomínios residenciais do Programa Minha Casa Minha Vida, e participantes de movimentos e coletivos de mulheres de Blumenau. Para promover o diálogo e a interação entre as participantes foram utilizadas diversas técnicas sugeridas pela metodologia de Ciocoletto (2014). A escolha desses diferentes perfis de mulheres trouxe diversidade de realidades, experiências e vivências com a cidade de Blumenau, possibilitando identificar as percepções, opiniões, necessidades e sentimentos sobre a sua participação e inclusão no processo de construção dessa cidade.

O resultado desta etapa da pesquisa subsidia o conteúdo da Carta das Mulheres para Blumenau, texto que traz os resultados dos diálogos promovidos durante os encontros com as mulheres que participa-
3 Disponível em: http://issuu.com/ punt6/docs/espaciosparalavidacotidiana. Acesso em 02 fev. 2016. 
ram da pesquisa - Lugares das Mulheres- exercício que identificou as percepções, demandas e reflexões sobre a cidade. Encerra-se com os desdobramentos desencadeados nos encontros com as mulheres que dela participaram, dos registros dos conteúdos discutidos e como o mesmo contribuiu para essas mulheres darem alguns passos em direção à conquista de seu direito à cidade.

A metodologia é realizada em três etapas:

1) diagnóstico participativo;

2) avaliação do espaço urbano;

3) avaliação da gestão urbana.

Como o objetivo foi levantar a percepção das mulheres em relação ao seu direito à cidade, essa metodologia não foi aplicada em sua integralidade, assim, foram utilizadas algumas ferramentas sugeridas na etapa do diagnóstico participativo. $\mathrm{O}$ diagnóstico participativo corresponde à primeira fase do processo de leitura da realidade, onde se obtém os dados junto às pessoas para avaliação dos espaços, incluindo aspectos físicos, sociais e funcionais. Neste caso, utilizou-se de metodologias qualitativas, a partir da perspectiva de gênero, para determinar em que condições se desenvolve a vida cotidiana das mulheres no espaço estudado.

Este método pode ser considerado como uma ferramenta de monitoramento da cidade em sua fase de diagnóstico, que se realiza com o cruzamento entre diferentes atores para incorporar eficazmente a dimensão cotidiana em que está inserida a perspectiva de gênero no planejamento urbano. Os indicadores propostos são decorrentes da necessidade de analisar e avaliar em que medida os elementos físicos dos diferentes espaços satisfazem as necessidades das pessoas que vivem no local estudado, incluindo dados qualitativos necessários para compreender a realidade e para que eles possam ser mensuráveis e comparáveis, tendo como resultado uma auditoria urbana, onde o relato dos usuários indica a situação e eficiência dos espaços da cidade, o que possibilita uma ação direta do usuário com as definições de política pública e intervenções urbanas.

Essas ferramentas podem ser aplicadas para diferentes fins, por exemplo, pedagogicamente como material de treinamento e capacitação da comunidade, ou também podem ser utilizadas como ferramentas analíticas e de avaliação em fase de planejamento. Podem ser usadas tanto pela comunidade quanto por profissionais e técnicos ligados a um projeto urbanístico específico, que queiram verificar o impacto em diferentes grupos sociais. As etapas sugeridas por Ciocoletto (2014) para realizar o diagnóstico participativo são:

a) percurso de reconhecimento;

b) observação participante;

c) dinâmicas participativas;

d) entrevistas.

Cabe ressaltar que o recorte espacial definido para esta pesquisa envolveu o território da cidade de Blumenau como um todo, confrontando as diversas realidades sócio-espaciais em que vivem os grupos de mulheres participantes. O objetivo é ter uma percepção geral das mulheres em relação ao seu direito à cidade. Desta forma, as ferramentas escolhidas para serem aplicadas, foram: 
a) "Percurso de Reconhecimento": Consiste em realizar, com grupos de pessoas envolvidas na pesquisa, caminhadas a pé, para fotografar e anotar diferentes situações encontradas. Essa atividade pode ter vários enfoques para observação. Ciocoletto (ob. cit.) ressalta que essas ferramentas de aproximação e interação com a realidade espacial estimulam uma maior compreensão sobre seus direitos, servindo como prática pedagógica e de tomada de consciência por parte dos cidadãos. Neste sentido, ela também ressalta a importância de divulgar e socializar os resultados das oficinas, fotografias, textos etc., com o restante da comunidade. No caso desta pesquisa, este exercício teve enfoque na temática da segurança da mulher na cidade de Blumenau. Foi realizado um mapeamento online 4 cujo objetivo foi identificar os lugares que passam sensação de insegurança. Essa ferramenta permitiu realizar um mapeamento coletivo dos locais compreendidos como inseguros para as mulheres em Blumenau.

b) "Diagnóstico urbano de gênero (DUG)": Trata-se de um questionário detalhado, que busca complementar a atividade do percurso percorrido. Essa etapa foi aplicada através de uma pesquisa online, intitulada Lugares das Mulheres: Diagnóstico Urbano de Gêenero, ${ }^{5}$ com perguntas desenvolvidas a partir do material sugerido pelo método em questão.

c) "Dinâmicas participativas": As dinâmicas participativas são um conjunto de atividades que se desenvolvem por meio da colaboração do usuário da cidade, com o objetivo de saber sobre seus comportamentos, hábitos e necessidades, como se dá a experiência do usuário em relação ao funcionamento dos espaços da cidade. Esta etapa ocorreu utilizando a ferramenta do World Café, a qual se trata de uma dinâmica que possibilita gerar insights, registros verbais, escritos e mapas sobre a questão-problema, tendo como foco descobrir e gerar conhecimento coletivo. As dinâmicas participativas World Café foram realizadas com as mulheres dos locais e com perfis determinados anteriormente, e a fase da pesquisa online foi aplicada a partir dos contatos nas redes sociais das mulheres que participaram das atividades presenciais, atingindo, assim, uma rede maior de mulheres. Em números, os encontros presenciais reuniram 55 mulheres, a pesquisa online teve a participação de 51 mulheres no questionário "Lugares das $\mathrm{Mu}$ lheres: Diagnóstico Urbano de Gênero", e 41 mulheres participaram do mapeamento coletivo dos espaços de insegurança, envolvendo um total de 147 mulheres.

Para nortear todos os conteúdos trabalhados na elaboração das ferramentas selecionadas (Percurso de Reconhecimento, Diagnóstico Urbano de Gênero e Dinâmicas Participativas), a pesquisa se dividiu em três eixos temáticos e os resultados são analisados utilizando-se de cinco conceitos de qualidade urbana, que Ciocoletto (2014) considera necessários para uma boa adequação dos espaços da cidade para a vida cotidiana.

Os eixos estudados podem ser assim caracterizados:

1) "Bairro e rede coletiva": Área determinada por um limite dentro do tecido urbano da cidade com uma determinada população residente e características particulares. A rede cotidiana significa a relação entre os espaços e os equipamentos utilizados no cotidia-
4 Formulário para o mapa coletivo sobre segurança na cidade disponível em: https://docs.google.com/forms/ d/1bSV84mVc7rq7dPNU3nE1Q4Z_IeTfmLL1GhKzrpz-QAY/edit?uiv=1.

5 Formulário para o Diagnóstico Urbano de Gênero disponível em: https:// docs.google.com/forms/d/1uvOlxtGMlarDiFTM39NAd0CstnmlQrXo3Isjh6yFT64/edit?uiv=1. 
no, onde as pessoas vivem suas realidades, como comércio, ponto de ônibus, ruas, espaços públicos.

2) "Espaços de relação": São os espaços onde as pessoas interagem durante a realização de suas atividades cotidianas no entorno urbano, como calçadas, praças, esquinas, parques, ruas.

3) "Equipamentos Cotidianos": São equipamentos indispensáveis, utilizados diariamente pelas pessoas do bairro como suporte para desenvolverem suas atividades da vida cotidiana.

Cada eixo se define com os seguintes conceitos de qualidade urbana: a) proximidade, b) diversidade, c) autonomia, d) vitalidade e e) representatividade. Considera-se qualidade urbana as características necessárias para que o espaço urbano ofereça uma experiência positiva do cotidiano para as mulheres.

Ciocoletto (2014) define os conceitos de qualidade urbana como:

a) Proximidade: Relação da distância em relação ao tempo percorrido entre os equipamentos da cidade, utilizados para realizar as tarefas cotidianas de reprodução, produção e comunitária, considerando sua fluidez, conectividade entre as casas, comércio e equipamentos públicos, e levando em conta os meios de transporte disponíveis acessíveis a qualquer pessoa.

b) Diversidade: capacidade que o espaço oferece de promover a mistura social, física e funcional que permite o uso por uma variedade de pessoas, incitando diferentes atividades de uso e que atenda a variadas necessidades de pessoas, suas condições de gênero, idade, sexo e origem.

c) Autonomia: é a condição que o espaço oferece para ser utilizado por qualquer pessoa com segurança, ser acessível para todas as pessoas, independentemente de qualquer condição física, limitações motoras ou que estejam com equipamentos de apoio.

d) Vitalidade: é a capacidade de reunir, simultaneamente, a presença de pessoas diferentes envolvendo-se em atividades de interesse diverso. São espaços que estimulam os encontros e as trocas sociais, comerciais, culturais e políticas.

e) Representatividade: a representatividade acontece quando se percebe e se tem o reconhecimento real e simbólico por toda a comunidade de modo a valorizar a memória, o patrimônio social das pessoas no processo de decisão urbana.

Com a intenção de capturar as percepções das mulheres em seu cotidiano em relação aos espaços e infraestrutura da cidade, essa metodologia nos ajuda a compreender como a vida se desenvolve na cidade, no desempenho de diferentes tarefas e papéis estudados anteriormente, como a reprodução, produção entre homens e mulheres, dentre outros. Pode-se dizer que a metodologia proposta por Adriana Ciocoletto, ao envolver o usuário da cidade, traz esse recorte de gênero e disponibiliza um conjunto de ferramentas de interação e de trocas, aproximando os usuários da cidade com a sua própria realidade e desencadeando processos transversais de ações, em nível estrutural, de políticas públicas e de gestão pública. 
Lugares das Mulheres: A percepção das mulheres de Blumenau sobre seu direito à cidade: descrição e análise dos encontros do World Café

Aqui serão relatadas as experiências dos encontros do World Café, encontros esses que visaram promover um diálogo entre os grupos de mulheres que participaram da pesquisa, seguindo de um registro coletivo de suas percepções sobre seus direitos à cidade. Os encontros aconteceram durante o primeiro semestre de 2016 em diversos locais. Foram realizados seis encontros presenciais, envolvendo 55 mulheres da cidade de Blumenau com diferentes perfis socioeconômicos.

É importante relatar como foram estabelecidos os contatos e os critérios para organizar esses encontros entre os diferentes grupos de mulheres que participaram da pesquisa. Foram previstos três grupos distintos de mulheres -acadêmicas de arquitetura, movimento de mulheres e moradoras de bairro, incluindo alguns condomínios residenciais do programa habitacional Minha Casa Minha Vida. Com essa estrutura, deu-se a trajetória de contatos com as respectivas lideranças e os encontros foram sendo agendados conforme a disponibilidade dos grupos. Vale ressaltar que os grupos de mulheres definidos para compor a pesquisa não foram determinados pela localização geográfica, o critério principal para a escolha dos grupos foi o perfil socioeconômico e nível de engajamento com as questões das mulheres.

O contato com as moradoras dos condomínios Minha Casa Minha Vida se deu através de encontros organizados pelas assistentes sociais da Painel, empresa contratada pela Caixa Econômica Federal para realizar atividades de integração social em alguns condomínios da cidade. Neste caso, o World Café aconteceu como uma atividade de integração e capacitação comunitária para as moradoras do Condomínio Residencial Parque Paraíso, no bairro Passo Manso, com a participação de 14 mulheres e do Condomínio Parque das Nascentes II, no bairro Progresso, onde aconteceram dois encontros, tendo o primeiro 9 participantes e o segundo, 10.

$\mathrm{O}$ encontro com as mulheres moradoras do bairro Itoupavazinha se deu através do contato com uma professora do Centro de Educação Infantil (CEI) Robert R. Barth, que organizou em sua casa e convidou algumas amigas e vizinhas para participarem, totalizando 7 mulheres.

Com o grupo de mulheres do curso de arquitetura, o World Café foi realizado como uma atividade durante o evento promovido pela rede de mobilização Minha Blumenau, integrando a programação do Circuito Mulheres Mobilizadas. Esse circuito reuniu, ao longo do mês de março de 2016, várias atividades para discutir os direitos das mulheres num âmbito geral na cidade de Blumenau. Foram várias temáticas abordadas por diversos grupos e coletivos de mulheres. Como o tema da discussão sobre o direito à cidade foi promovido no local conhecido como Galpão da Arquitetura da FURB, acabou concentrando um maior número de alunas da arquitetura, somando um total de 5 participantes.

O encontro com as mulheres representantes dos movimentos e coletivos foi realizado em uma atividade organizada pela pesquisadora e o Coletivo LEENA-Mulheres da Arquitetura durante programação do Ateliê Vertical 2016, atividade integradora do curso de Arquitetura e Urbanismo com a comunidade. Neste encontro, a atividade do World Café contou com a presença de 10 mulheres de outras áreas da FURB e de coletivos da cidade, como representantes da Casa da Mãe 
6 O Coletivo Feminista Casa da MãeJoana é uma organização feminista criada em junho de 2013 em Blumenau. Busca reunir as mulheres da região para grupos de estudos, ações, panfletagens, palestras e eventos em geral para divulgar o feminismo e articular estratégias para libertação feminina.

7 O Movimento Lilás é um movimento de mulheres cujo propósito é articular e promover momentos de encontro e diálogo entre os coletivos feministas, grupos de mulheres e comunidade para discutir as pautas das mulheres em Blumenau -ocupando os espaços, seja das praças ou de qualquer outro para conectar as pessoas, resgatar e ressignificar o caráter público, coletivo, político, pedagógico e de lazer dos espaços públicos da cidade. Criado em abril de 2016.

8 UBM-União Brasileira de Mulheres é uma entidade nacional, sem fins lucrativos, que luta pelos direitos e emancipação das mulheres, visando a construção de um mundo de igualdade contra toda opressão.

9 Acesso à dissertaçãohttp://www.bc. furb.br/docs/DS/2017/362562_1_1.pdf. 10 O acesso para o ambiente virtual do grupo Lugares das Mulheres na rede social Facebook está disponível em: https://www.facebook.com/ groups /737144309720514/?fref=ts. 11 Grupo virtual "Lugares das $\mathrm{Mu}$ lheres", disponível na rede social Facebook em: https://www.facebook.com/ groups $/ 737144309720514 /$ ?fref=ts.
Joana, ${ }^{6}$ Mulheres do Movimento Lilás ${ }^{7}$ e União Brasileira de Mulheres $(\mathrm{UBM}){ }^{8}$

Importante ressaltar que a fase de contato com representantes dos grupos para estruturar os encontros foi um momento de trocas significativas entre as participantes, uma vez que a maioria se interessou pelo tema por nunca terem tido a oportunidade de fazer tal debate. Os relatos foram transcritos e encontram-se disponíveis no corpo da dissertação ${ }^{9}$ de Sarmento (2017) e contextualizam cada encontro e destacam as principais narrativas.

Todas as mulheres que vieram para os encontros foram convidadas a participar do grupo do Facebook denominado Lugares das Mulheres, ${ }^{10}$ grupo online criado para conectar as mulheres que participaram dos encontros e promover o acompanhamento das mesmas ao longo dos debates e desfechos da pesquisa. Esse ambiente ajudou a estabelecer uma rede entre as mulheres, uma vez que o debate continuou com diversos grupos.

Todos os encontros seguiram a mesma estrutura, desta forma, cabe detalhar as etapas dos encontros como padrão para todos os grupos. Foi entregue um roteiro para cada grupo com uma breve introdução para o exercício, destacando o objetivo de discutir coletivamente os direitos das mulheres à cidade na condição de usuárias, bem como perceber quais são as principais demandas para o desenvolvimento da rotina cotidiana e quais contribuições trariam para o planejamento urbano da cidade de Blumenau.

Sobre a condução do exercício, cada grupo teve uma anfitriã que se manteve fixa na mesa com a função de registrar, na folha branca, todas as palavras-chave na coleta das informações e falas do grupo. No formato original do World Café, a cada pergunta é feito um rodízio entre os participantes, ficando a anfitriã fixa na mesa para realização da coleta, porém como a quantidade de participantes foi pequena em cada encontro, esse rodízio não foi possível. Manteve-se, então, a anfitriã para realizar os registros e as perguntas foram discutidas com o mesmo grupo do começo ao fim da atividade. Foram três perguntas com uma média 15 a 20 minutos de diálogo cada. Somando-se ao tempo de introdução e fechamento das discussões, os encontros tiveram em média uma hora e meia de duração. Desta forma, as perguntas que nortearam os diálogos foram as seguintes:

1) Blumenau atende seu direito à cidade? Identificar as principais limitações que impedem as mulheres de exercerem seu direito à cidadania, à qualidade de vida e à emancipação.

2) Considerando a rotina do seu dia-a-dia, como você solucionaria os principais problemas levantados na questão anterior? Identifique, por ordem de prioridade, quais questões devem estar na carta das mulheres para cidade.

3) Quais alternativas e soluções as mulheres incluiriam no planejamento da cidade?

\section{Lugares das Mulheres: Diagnóstico urbano de gênero}

Com a finalização dos encontros de World Café, foi criado um grupo temático "Lugares das Mulheres-ambiente virtual da pesquisa". ${ }^{11}$ Este ambiente foi criado na plataforma F acebook com objetivo de fomentar a discussão sobre o direito das mulheres à cidade a partir das discussões 
que foram promovidas junto com o grupo de mulheres que participaram da pesquisa presencial.

Seguindo uma recomendação sugerida no capítulo 3 do livro Mujeres Trabajando, material desenvolvido pelas arquitetas do ColletiuPunt6, que sugere mecanismos para a divulgação e compartilhamento das experiências vivenciada, esse ambiente virtual possibilitou o acesso de mais de 270 mulheres ao conteúdo discutido durante a pesquisa presencial. Foi neste local que os formulários da etapa da pesquisa online "Lugares das Mulheres: Diagnóstico urbano de gênero", ${ }^{12}$ foram aplicados e ficaram disponíveis durante 4 meses, recebendo um acesso total de 92 mulheres que responderam aos dois questionários online.

Na Figura 1 estão identificados os bairros que tiveram participação das mulheres. Cabe ressaltar que o público que participou dessa fase da pesquisa online não é o mesmo que participou da fase da pesquisa presencial nos encontros do World Café.

As perguntas foram desenvolvidas de forma a responder os três eixos sugeridos pela metodologia estudada. Com esse exercício, foi possível perceber que, mesmo que tenha sido aplicado a mulheres de diversas regiões da cidade (Figura 1) e que os temas abordados tenham sido os mesmos que fundamentaram a discussão presencial, a maioria das percepções se repete, apontando que os problemas enfrentados pelas mulheres para exercerem seu direito à cidade estão relacionados a questões estruturantes e transversais aos limites e ao funcionamento da cidade. É possível identificar nas análises que se apresentam a seguir (Figuras 2 e 3), uma representação das respostas objetivas e descritivas que foram sugeridas no questionário.

Sobre o entendimento do bairro em rede, onde se apresenta as condições da cidade para os usuários poderem desenvolver suas atividades cotidianas, ao serem questionadas sobre a qualidade de suporte da cidade para realização de suas tarefas cotidianas, bem como sobre a capacidade de mobilidade e acesso, pontos positivos e negativos e sugestões, as respostas se apresentaram da seguinte forma:

Sobre as questões elaboradas para compreender a percepção sobre o espaço relacional, que significa a forma como são utilizados os espaços e as condições enfrentadas para que trocas sociais e as atividades do cotidiano aconteçam, duas questões foram destacadas: a dificuldade de acesso à cidade e a insegurança para utilizá-la. Através da técnica Percurso de Reconhecimento, sugerida por Ciocoletto (2014),

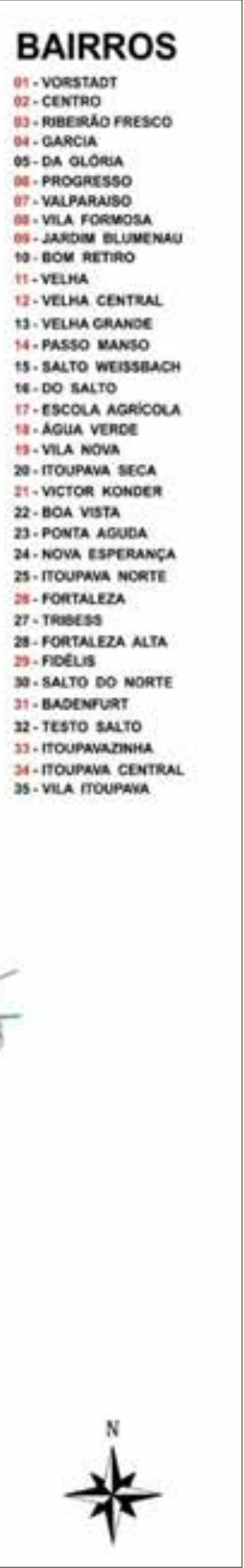

Figura 1: Mapa das Regiões geográficas de Blumenau, com a marcação de todos os bairros que foram acessados na pesquisa online Lugares das Mulheres: diagnóstico urbano de gênero. Fonte: FURB (2015), adaptado pela autora.

12 Acesso aoformulário online da pesquisa, disponível em:"Lugares das Mulheres: Diagnóstico urbano de gênero"https://docs.google.com/a/terra.arq.br/ forms/d/e/1FAIpQLScz1Gsh-oLVIwCiYZLYxDwDW0Ak-_84aG18JqHKL3-k6HZL$\mathrm{Vg} /$ viewform? $=0 \& \mathrm{w}=1$.

13 Acesso ao formulário online da pesquisa "Lugares das Mulheres: espaços de insegurança na cidade", disponível em:https://docs.google.com/a/terra.arq.br/ forms/d/e/1FAIpQLSdbraRTPzFG660PQgoVzlJ9wF43tFjcT58kiFrbnj8Imdydtg/ viewform? $\mathrm{c}=0 \& \mathrm{w}=1$. 


\section{Você tem algum periodo do dia que prefere näo utilizar a cidade a pé?}

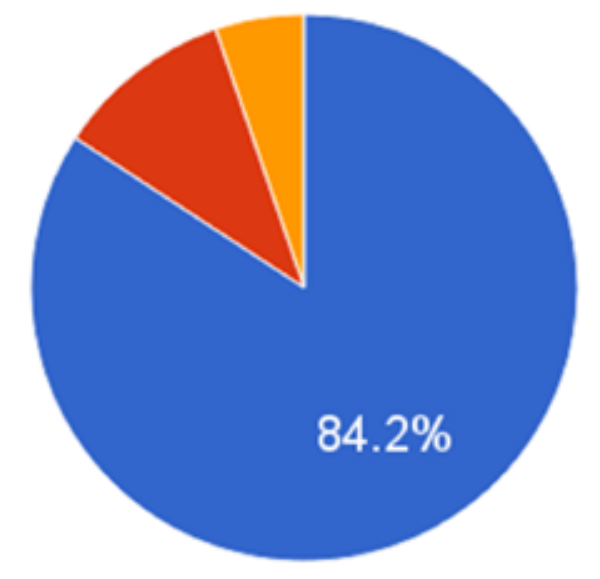

Parcialmente

Năo

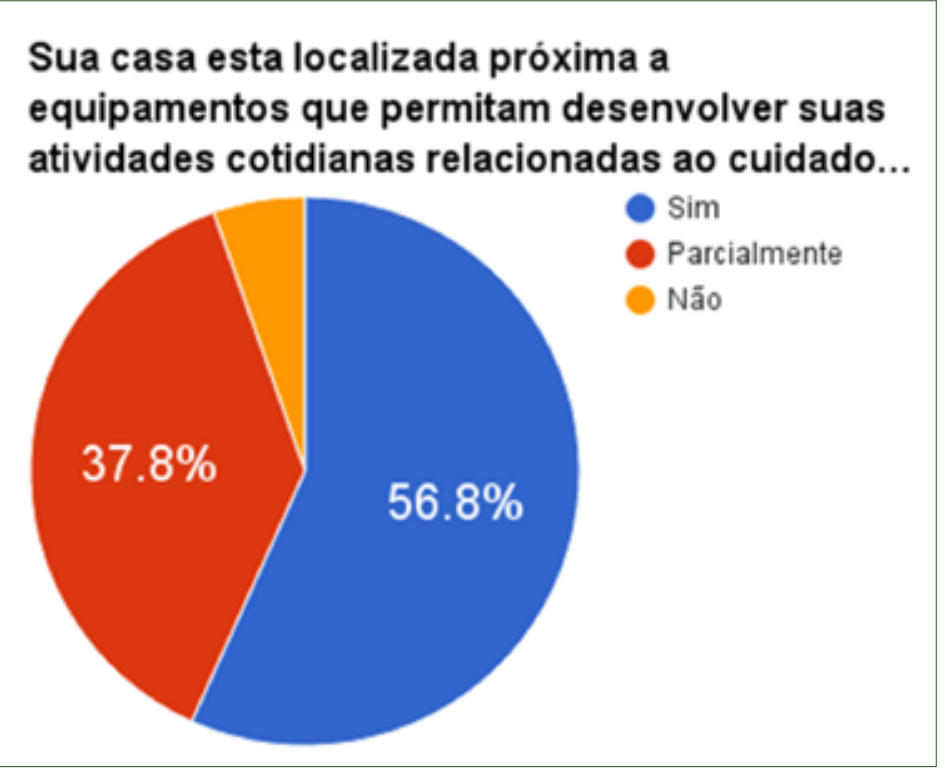

Figura 2: Resultado dos questionários sobre as condições da cidade em rede. Fonte: Autora.

Figura 3: Resultado sobre a preferência das usuárias pelo meio de locomoção para realização de suas atividades diárias. Fonte: Autora.

\section{Caso sua resposta tenha sido positiva na pergunta anterior, indique o periodo.}

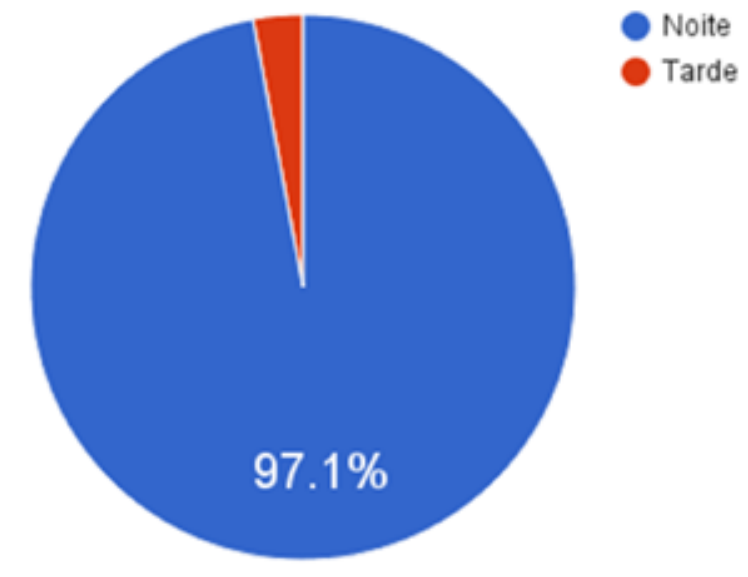

foi desenvolvido um formulário "Lugares das $\mathrm{Mu}$ lheres: espaços de insegurança na cidade" ${ }^{13} \mathrm{com}$ o objetivo de construir um mapa coletivo sobre os espaços inseguros de Blumenau percebidos pelas mulheres ao longo do dia e da noite, enquanto utilizam a cidade para realização de suas atividades. O resultado apontou os lugares percebidos e, com isso, se identifica uma alternativa online de ferramenta de informação que pode ser utilizada como base para a implementação de políticas públicas de segurança.

A técnica supracitada desenvolvida neste exercício apresentou um exemplo prático de como é possível aplicar a questão de gênero na gestão urbana, tendo como objetivo solucionar os problemas dos locais inseguros da cidade, identificados pelas mulheres, mas que trarão benefícios a todos. Os locais inseguros identificados coletivamente pelas 41 mulheres que responderam a esse formulário específico apresentam o seguinte resultado na Figura 4:

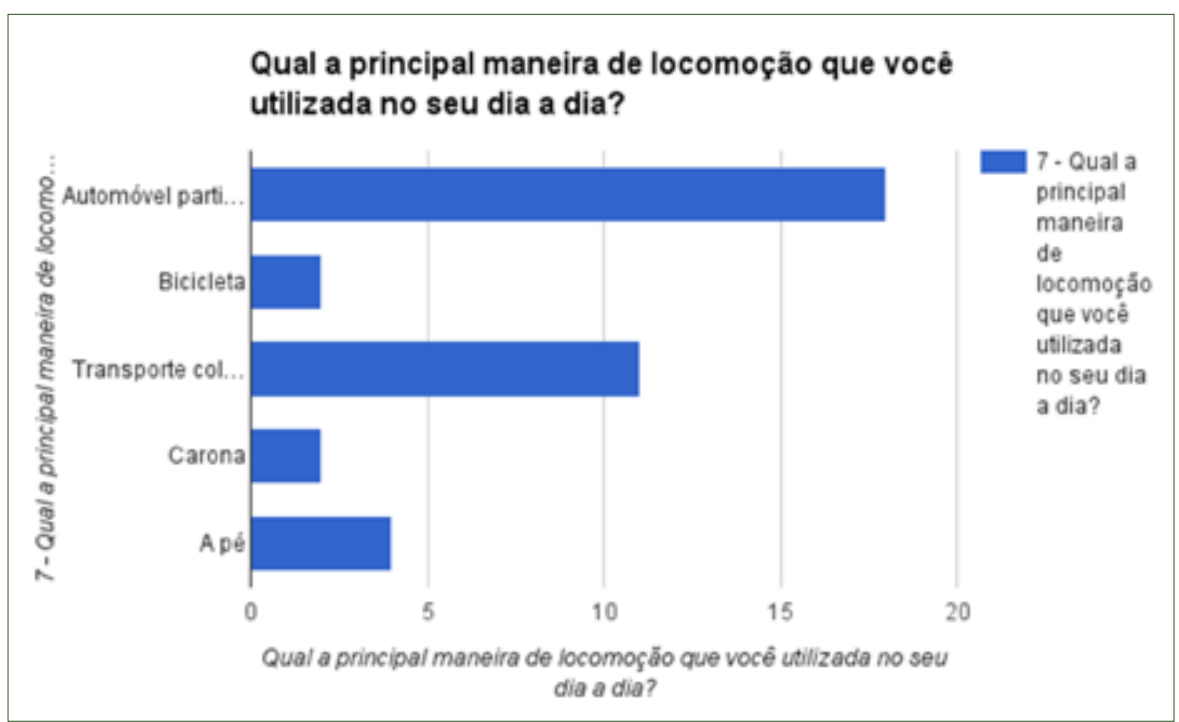




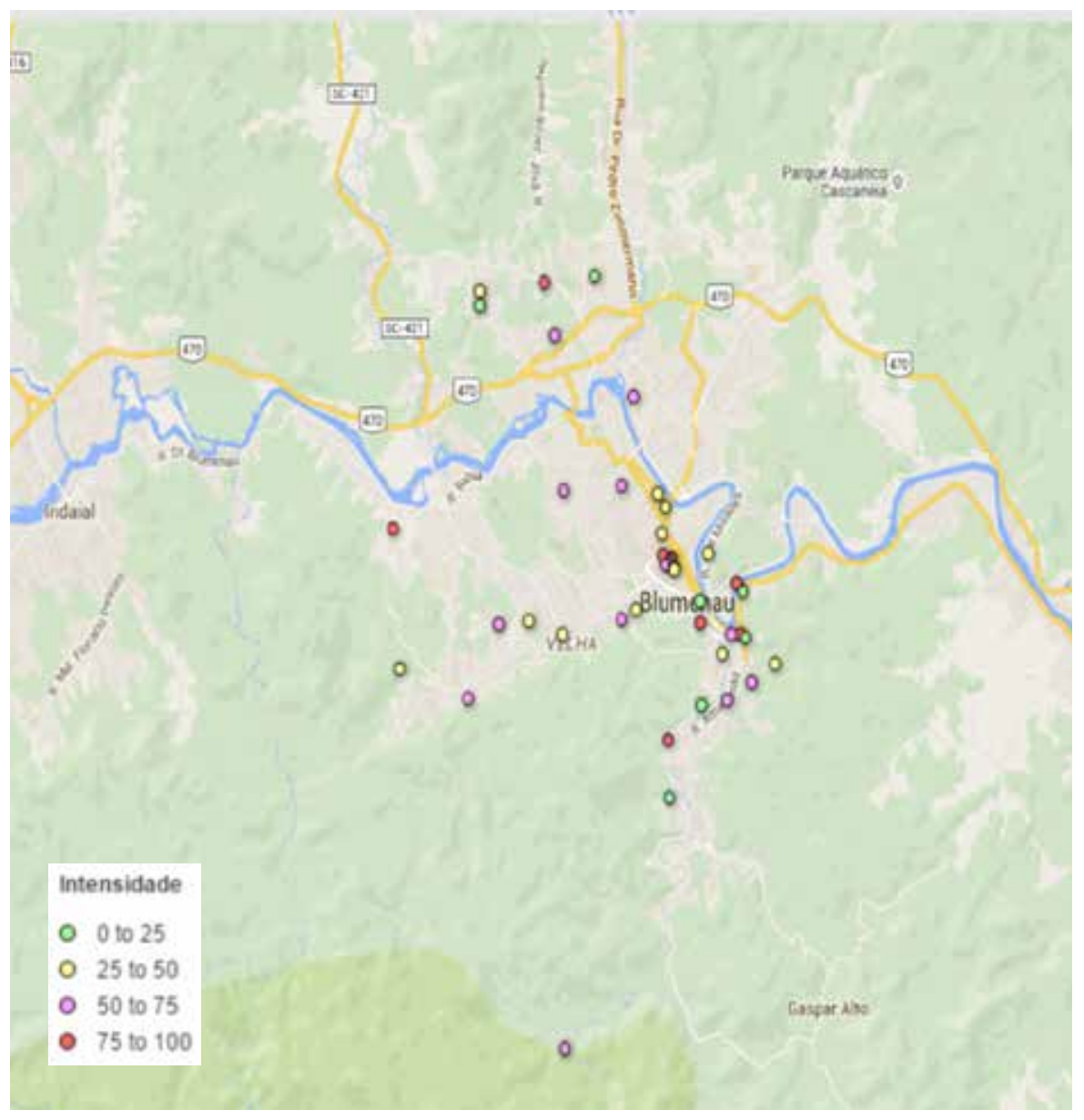

Neste exercício, ${ }^{14}$ apresentado na Figura 4, é possível levantar, além do local considerado inseguro, a intensidade do medo e o motivo da escolha do local, como aparece na Figura 5. Dessa forma, foi possível obter informações detalhadas das condições dos locais e qual ação é necessária para melhorar o espaço.

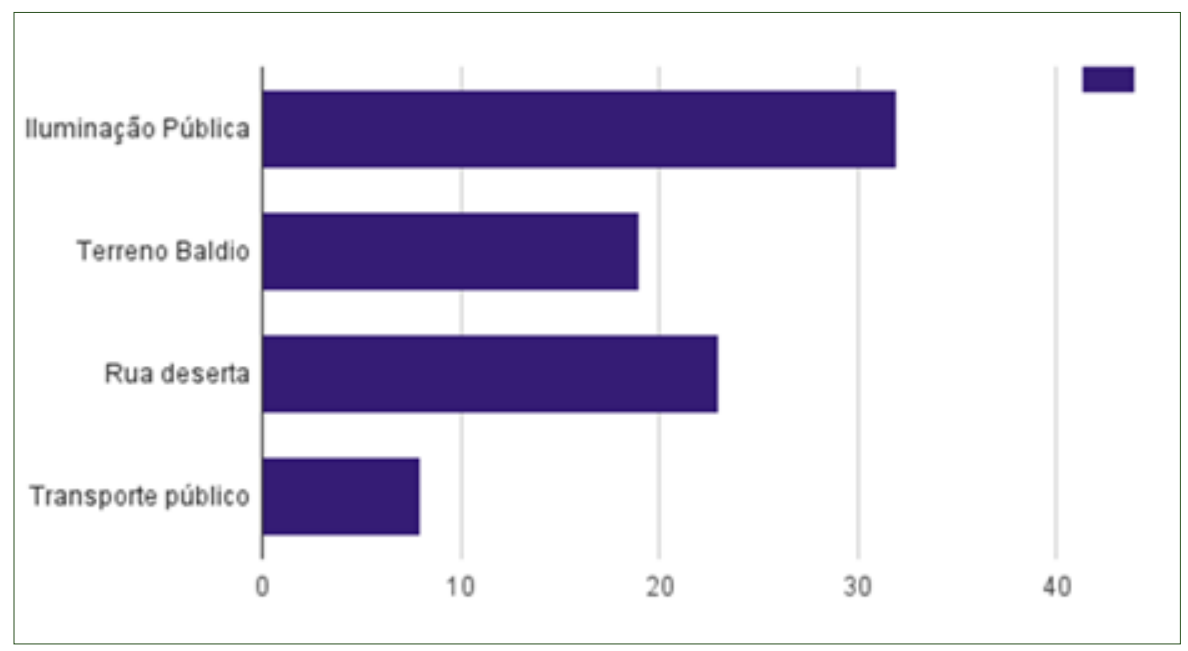

O terceiro bloco de perguntas foi estruturado para levantar a percepção das usuárias da cidade em relação à disponibilidade dos equipamentos públicos, que são os espaços onde as atividades públicas são oferecidas. Coube investigar, nesta etapa, se os mesmos são suficientes, por quem são utilizados e quais atividades são oferecidas. Os resultados podem ser conferidos na Figura 6:
Figura 4: Mapa com a marcação dos locais citados pelas mulheres que participaram do formulário para construção do mapa coletivo. Fonte: Mapa gerado pelo formulário da pesquisa, elaborado pela autora.

Figura 5: Principais características dos locais indicados no formulário Lugares das Mulheres - Mapa Coletivo que geram a sensação de insegurança percebida pelas usuárias. Fonte: Autora.

14 Resultado completo do formulário Lugares das mulheres - Mapa coletivo encontra-se disponível em: https:/ / docs. google.com/spreadsheets/d/1HcQL6NqLZH9f8MB5mkW0QlEYOChMKySCA9_ vyv08xHo/edit\#gid=541306074. 
Figura 6: Resultado das perguntas sobre a disponibilidade e condições dos equipamentos públicos. Fonte: Autora.
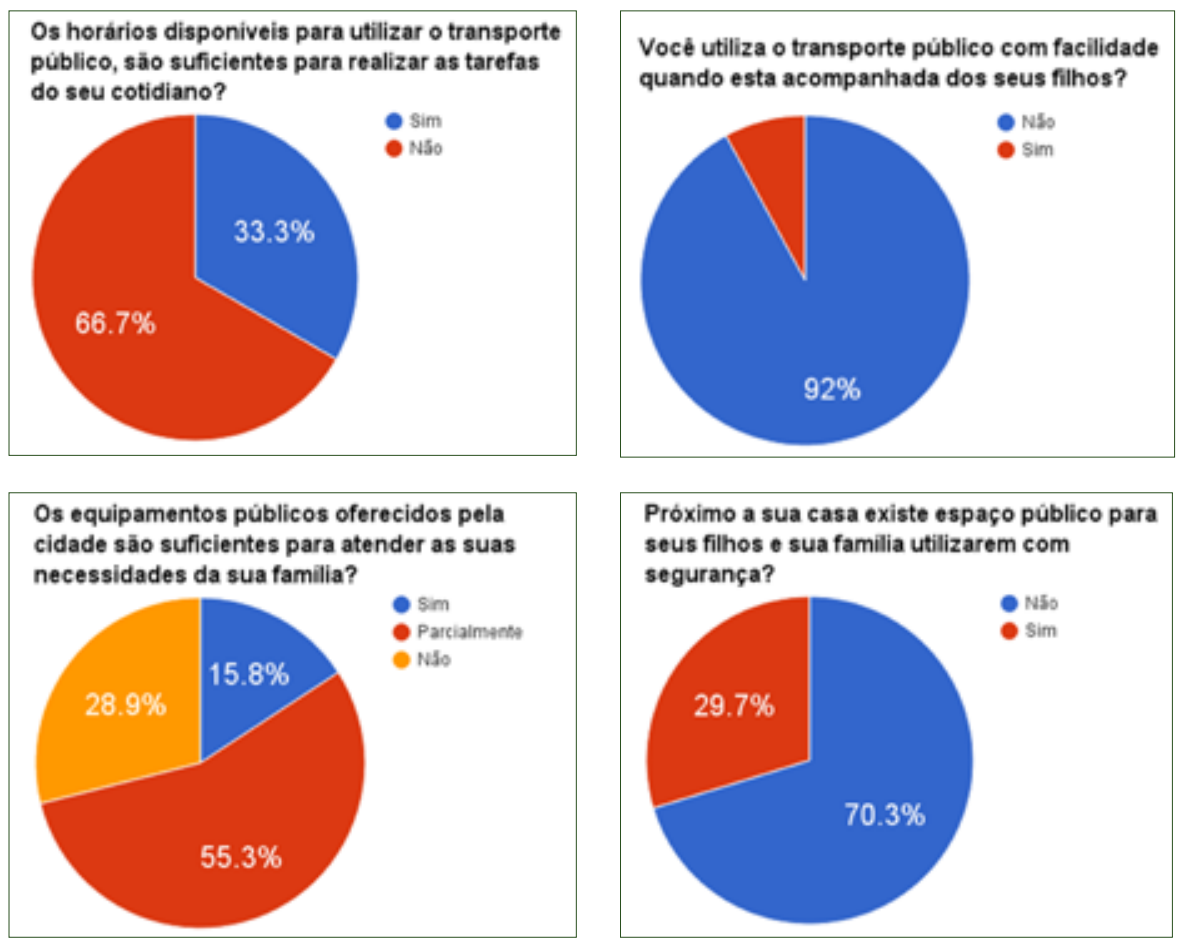

Complementando as perguntas objetivas, cujo resultado foi apresentado nos gráficos anteriormente, foram formuladas três perguntas descritivas: ${ }^{15}$ uma questionando sobre a percepção do seu direito à cidade, outra sobre as principais dificuldades encontradas para realização das atividades do cotidiano e uma terceira, solicitando sugestões de prioridades e soluções para a cidade.

Sobre a primeira pergunta, a maioria das mulheres percebe que o direito à cidade está relacionado ao acesso de todos os cidadãos aos espaços e equipamentos públicos da cidade, além da capacidade de ter mobilidade com segurança e a oportunidade de participar das decisões da cidade. Destaca-se, em algumas respostas, o sentimento de não terem esse direito atendido e o baixo índice de participação no Plano Diretor, visto que apenas 20,3\% das entrevistadas acusaram ter participado de alguma atividade do Plano Diretor. Cabe ressaltar que nas entrevistas presenciais a maioria das mulheres respondeu da mesma forma, como pode ser verificado nos seguintes comentários registrados:

Fico à margem da cultura, do esporte e do lazer. Meu lugar é na fábrica, na cozinha e na igreja.

Todo cidadão tem deveres e direitos quanto à sua cidade. Na atual situação, penso que nossos direitos não estão sendo respeitados, tão pouco compreendidos pelos responsáveis.

Ao responderem à pergunta sobre as principais dificuldades encontradas para realizarem suas atividades cotidianas, a questão da acessibilidade foi a mais citada. Relatam sobre a necessidade de ter mais horários de ônibus disponíveis ao longo do dia, a necessidade de ter um sistema de ciclovias que dê condições de circular com segurança e a condição das calçadas, que se apresentam em péssimas condições e sem arborização. Esses três pontos — transporte público, ciclovias e calçadas arborizadas - foram as questões mais abordadas pelas usuárias da cidade que participaram da pesquisa. Este dado aponta que a mobilidade oferecida pela cidade, hoje, não oferece condições suficientes
15 Resultado completo do formulário Lugares das mulheres - Mapa coletivo encontra-se disponível em: https://docs. google.com/spreadsheets/d/1KNOWQH6tuzDbwBJzXSksWoGAA3x1-i8UGCoXMZ5lQIg/edit\#gid=702739620. 
para as mulheres desenvolverem suas atividades cotidianas com segurança. Os relatos revelam a disposição de realizarem suas atividades utilizando esses meios citados, mas não o fazem por não se sentirem seguras e pela falta de estrutura suficiente:

Não é em todas as ruas da cidade que possui espaço para os pedestres caminharem. Poucos horários de ônibus para a região aonde moro, além de não me sentir muito segura, às vezes, para ir a pé a algum local que seja próximo da onde moro.

Mesmo com essas dificuldades, eu ainda faço, porque preciso e quero. Mas, se fosse uma pessoa de idade, uma mãe com crianças, ou uma pessoa deficiente, esses três pontos dificultam muito mais o cotidiano.

Sobre a relação de prioridade e sugestões, foi muito citado a necessidade de ter as calçadas revitalizadas e arborizadas, mais espaços de lazer e cultura. Sugerem também a descentralização dos equipamentos públicos para facilitar o acesso próximo aos bairros, pois consideram que a centralização dificulta a mobilidade diária quando necessitam utilizar tais equipamentos. Melhoria e ampliação de horários para o transporte público.

A percepção geral das mulheres que participaram da pesquisa, quando questionadas sobre as principais qualidades da cidade, aponta para as seguintes questões: sobre a diversidade de uso, chama a atenção o fato de que vários comentários trazem como vantagem a presença do comércio espalhado pela cidade. Nessa lógica, justifica-se porque apontam a necessidade de descentralizar também os equipamentos públicos. Complementando essa questão do uso da cidade e defendendo a necessidade da proximidade dos equipamentos como um facilitador para a realização das atividades cotidianas, há também a necessidade do transporte coletivo, com a mesma função: agilizar a mobilidade entre a diversidade de atividades realizadas pelas mulheres ao longo do dia. Destacam a presença da Universidade como um fator positivo para o desenvolvimento do conhecimento. A beleza da paisagem e a qualidade ambiental também aparecem como elementos positivos da cidade e, mesmo que faltem árvores nas calçadas, valorizam o fato de a cidade ter seus parques naturais preservados.

Assim, é possível concluir que as percepções e demandas levantadas nos dois exercícios de pesquisa, tanto nos encontros do World Café como no espaço online, trouxeram reflexões e apontaram para questões similares, onde a questão da segurança, mobilidade e os espaços de uso público foram os pontos mais discutidos entre as usuárias da cidade.

Cabe ressaltar a disposição das mulheres participantes em querer participar dos espaços de decisão, mas não terem tempo, e também o fato de que a maioria das mulheres não sabia o que era o Plano Diretor e também não tinha parado para pensar ou conversar sobre o seu direito à cidade. Desta forma, os relatos reforçam as questões discutidas nos capítulos anteriores, onde fica clara, em vários momentos, a condição da mulher de viver em função da reprodução, do seu condicionamento ao espaço privado, da dificuldade de fluir na cena pública, do enfrentamento do medo e da insegurança. A discussão que se abre com essa experiência coletiva é a necessidade de pensar a cidade com as mulheres. Além, claro, do desafio de buscar metodologias de participação que possibilitem incluir, a experiência de viver a cidade e considerar a necessidade de todos. 


\section{Carta das Mulheres para a Cidade de Blumenau: as demandas das mulheres para a construção de políticas urbanas}

Com o resultado dos diálogos que se desenvolveram nas rodas de conversa do world cafée pesquisa online realizadas ao longo da pesquisa, foi possível escrever um documento com título, "Carta das Mulheres para a Cidade de Blumenau" que teve como objetivo sistematizar os principais tópicos discutidos e relacionados como prioridade pelas mulheres durante os encontros para realização da pesquisa. O texto completo da carta está disponível no seu endereço online. ${ }^{16}$ A seguir segue a lista de demandas que compões esse documento:

a) Sobre a participação da mulher na cidade

- Inclusão das questões de gênero na formulação da lei do Plano Diretor das cidades como um capítulo de caráter transversal e integrado com todas as secretarias do município.

- Estimular e criar condições para que as mulheres participem das discussões sobre a cidade, facilitando os horários, realizando os encontros em locais descentralizados, disponibilizando o espaço para as crianças poderem acompanhar as mães que não tem com quem deixar seus filhos durante as atividades.

b) Sobre a segurança das mulheres na cidade

- Incorporar, oficialmente, no sistema de equipamento urbano da cidade, espaço para acolhimento e apoio às mulheres vítimas de violência, incluindo a estruturação da delegacia da mulher, plantão de apoio e assistência social, bem como ampliar a quantidade de casas de apoio às mulheres.

- Criar lei responsabilizando donos de terrenos baldios e abandonados pela manutenção e constante limpeza, para mantê -los com boa visibilidade, pois esses espaços representam a principal causa de insegurança para as mulheres na cidade.

- Criar lei específica para incentivar que todos os prédios residenciais, comerciais e públicos, tenham abertura e uso prioritário virado para o lado da rua, evitando assim longos percursos vazios sem vitalidade.

- Criar plano de iluminação pública para dar visibilidade em locais mais distantes e isolados, próximo a pontos de ônibus e equipamentos públicos.

- Estimular a diversidade de uso nos bairros com atividades comerciais, culturais, de lazer, educacional e de saúde, com horários de funcionamento diversificados para atender a demanda das mulheres fora dos seus horários de trabalho.

c) Mobilidade e acesso à cidade para as mulheres

- Considerar como prioridade os investimentos em transporte público, pedonal e cicloviário.

- Criar sistema de transporte público que garanta mais horários para atividade da reprodução e mais segurança para idosos e crianças.

16 Texto completo da Carta das Mulheres para Cidade Blumenau encontra-se disponível em: https://drive.google.com/ drive/folders/0B7mTYxB83BTYbEFjMTVCeHpGMWM.

- Ampliar a disponibilidade de horários de ônibus, criando um sistema pautado nas diversas demandas das cidades e levandose em considerando a condição dos usuários, como, por exemplo, criar linhas exclusivas para estudantes, linha para interligar os equipamentos de saúde, ampliar os horários durante o final de semana para estimular os passeios e sociabilização. 
- Ter um plano de arborização e calçadas que deem condições de caminhabilidade para todos, inclusive mulheres gestantes, carrinhos de bebê, idosos, cadeirantes, deficientes visuais, e pessoas com mobilidade reduzida.

- Dar prioridade para implantação do sistema de ciclovias. A bicicleta representa um forte aliado à mobilidade para execução de todas as tarefas cotidianas, ligadas à reprodução e à produção, mas para as mulheres torna-se ainda mais especial, devido à possibilidade de se locomover com maior agilidade e autonomia.

- Disponibilizar os pontos de ônibus em locais iluminados e próximos de vitalidade. Permitir descida em qualquer lugar da cidade após as $20 \mathrm{~h}$ apenas para as mulheres.

d) Equipamentos públicos e gestão da vida cotidiana

- Criação de um sistema de equipamentos de ensino para atendimento em tempo integral para creches e escolas, articulados com espaços e programas de cultura, arte e lazer e cidadania complementares. Que os espaços educacionais sejam prioridade de investimento público nas cidades.

- Criar programa de incentivos fiscais, renda e suporte técnico para criação de renda e empreendedorismo para mulheres.

- Implantar, nos espaços públicos, estrutura para acolher mães, crianças e idosos, com infraestrutura de banheiros, fraldários e bebedouro.

- Reservar áreas verdes na cidade para implantação de parques e praças e áreas de preservação ambiental, com estrutura de lazer para todas as idades, atividades coletivas e educação ambiental para todas as idades.

- Utilizar com prioridade as áreas residuais da cidade, cedidas pelos loteamentos, para criar um sistema de micro praças e equipamentos públicos descentralizados, com diversidade de uso, como por exemplo: hortas comunitárias, feiras, parque infantil, campo de futebol, biblioteca, mini praças, pista de skate, patins, quadra de vôlei, etc.

- Implementar programas de segurança alimentar, criando sistema de hortas comunitárias, feiras livres com preços acessíveis e descentralizados na cidade, estimular a agricultura familiar e urbana.

e) Habitação

- Atender com urgência a falta de segurança vivida pelas famílias dos condomínios residenciais do Programa "Minha Casa Minha Vida" e moradores de áreas de risco, pois essa condição de vulnerabilidade afeta diretamente a vida de todos, mas, em especial, a vida das mulheres, por serem, em sua maioria, responsáveis pela administração do cotidiano e do sustento de suas famílias.

- Garantir e ouvir as mulheres moradoras das áreas de risco e conjuntos habitacionais para elaboração das políticas públicas habitacionais, assim como tornar os projetos habitacionais participativos.

O documento "Carta das Mulheres para a Cidade de Blumenau" foi lido e protocolado durante a realização da sexta Conferência Municipal das Cidades, em 04 de junho de 2016 na cidade de Blumenau, encontro este que trouxe como lema central "Cidades inclusivas, par- 

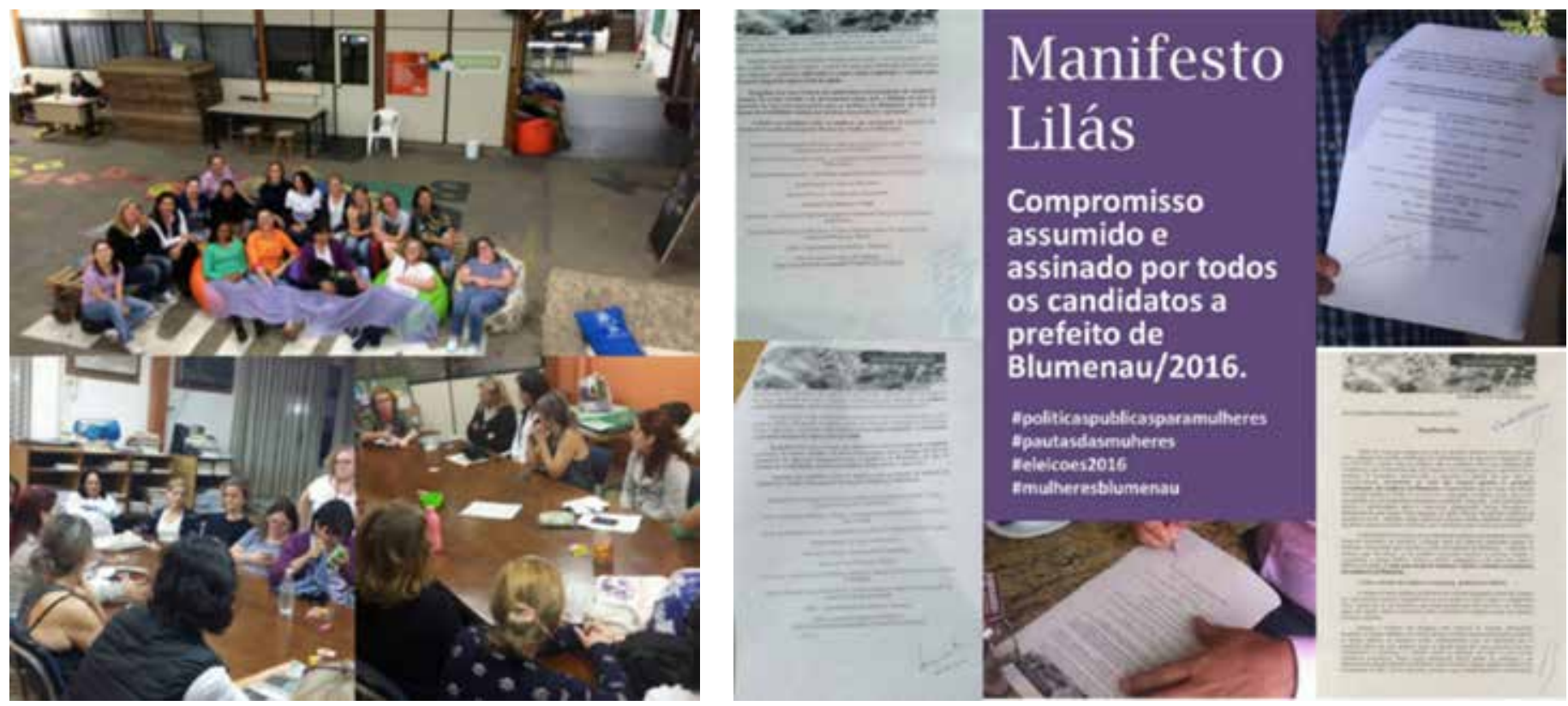

Figura 7: A imagem à esquerda traz o registro da reunião do Movimento Lilás, realizada no Galpão da Arquitetura sede do Curso de Arquitetura da FURB - Universidade Regional de Blumenau, no mês de setembro/2016 com representantes de diversos coletivos da cidade para elaboração do texto do Manifesto Lilás. A imagem à direita traz a imagem publicada pelo movimento com todos os manifestos assinados, divulgando o compromisso assumido pelos candidatos com as pautas das mulheres e apoio à criação do Conselho Municipal de Mulheres de Blumenau. Imagem inferior retrata a instalação pública feita pelas mulheres na Praça Lilás ${ }^{18}$ do mês de novembro/2016 na Praça Getúlio Vargas, no bairro Garcia. Fonte: Acervo online Movimento Praça Lilás (2016).
17 Conteúdo completo do ManifestoLilás. Disponívelem https://drive.google. $\mathrm{com} /$ drive/folders/0B7mTYxB83BTYbEFjMTVCeHpGMWM. Acessoem 20 jan. 2017.

18 Ambiente virtual movimento Praça Lilás,disponível em: http://www.pracalilasbnu.esy.es/. Acesso em 20 março. 2018. 19 Ambiente online com registro dos encontros e conteúdo promovido pelo Movimento Lilás. Disponível em: https:/ / www.facebook.com/pracalilasbnu/?fre$\mathrm{f}=$ ts.

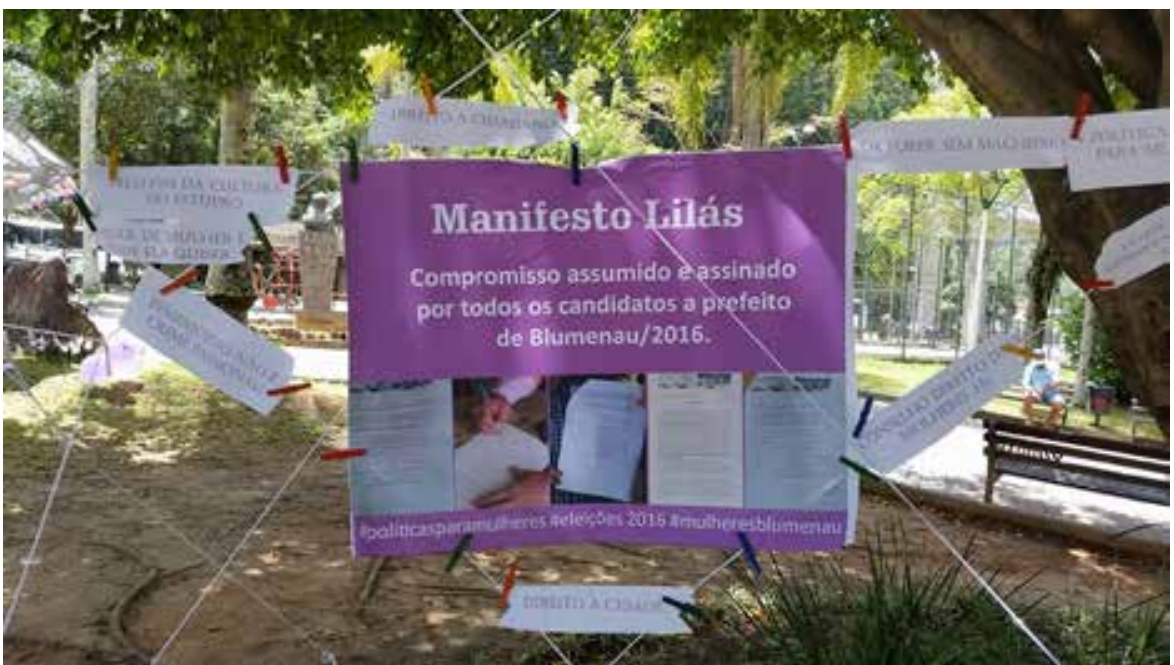

ticipativas e socialmente justas" tendo como objetivo identificar os problemas enfrentados na cidade e buscar, de forma participativa, soluções para ampliar e garantir o direito à função social da propriedade e garantir a qualidade de vida nas cidades. Neste evento o conteúdo da carta foi debatido e protocolado para ser encaminhado para o processo de Revisão do Plano Diretor de Blumenau e para a Conferência Estadual das Cidades. O conteúdo da carta, trazendo as demandas das mulheres sobre seu direito à cidade, integrou também o Manifesto Lilás ${ }^{17}$ (Figura 7), documento construído coletivamente, envolvendo diversos coletivos de mulheres que participam do movimento pela criação do Conselho Municipal de Políticas Públicas para as Mulheres de Blumenau, onde cada coletivo preparou um texto expressando suas reivindicações e demandas.

Durante esse processo, foi possível perceber, através do conteúdo discutido pelo tema proposto neste trabalho, como o entendimento de algumas mulheres sobre seu direito à cidade possibilitou o desencadeamento de algumas ações, como o surgimento da Praça Lilás, ${ }^{19}$ uma atividade sugerida e promovida pelos coletivos que participam do movimento pela criação do Conselho de Políticas Públicas para as Mulheres de Blumenau. 


\section{Conclusões}

As raízes predominantes na sociedade, que se expressam no espaço da cidade, anunciam a necessidade de uma desconstrução dos processos de exclusão, visando novas alternativas e possibilidades de fomentar a igualdade, a diversidade, a participação e a sustentabilidade. Uma alternativa é trazer para esse processo de desconstrução a perspectiva do pensamento feminista, como sugere Montaner (2012), uma vez que esse pensamento envolve uma visão de mundo que parte do valor da experiência pessoal, entendendo-se que todo pessoal é político. Assim, o resultado das relações pode ser a fonte de uma nova interpretação mais humanista do mundo, ao considerar as habilidades das mulheres em estar atentas com a realidade próxima e de apoiar as relações sociais, tendo resiliência e empatia, uma vez que a mulher se relaciona na perspectiva do outro. Porém, cabe perguntar: Como inserir a mulher no contexto de mudança, ter condições de falar, ser ouvida e compreendida? Essa é uma questão chave que se abriu a partir desse estudo.

Cabe aqui destacar o movimento de mulheres estabelecido em Blumenau, o que reforça o potencial e a disposição das mulheres em participarem das questões que foram levantadas ao longo do trabalho. Igualmente necessário apontar também a relevância de todos os coletivos de mulheres existentes na cidade e seu engajamento em diversas lutas acerca da vida das mesmas, mostrando, assim, que o movimento de mulheres de Blumenau está engajado em diversos temas da sociedade. A importância da expressão, da fala e da participação das mulheres no contexto da construção do território como caminho para uma nova relação de igualdade e de acesso aos direitos das mulheres, aponta a necessidade do aprofundamento em busca de alternativas para o fomento da participação dessas no contexto da construção da cidade. Desta forma faz-se necessário o aprimoramento dos processos de sensibilização, engajamento e fortalecimento dos movimentos sociais ancorados no conceito da participação cidadã.

Neste contexto, existe um universo a ser explorado, apoiado e estudado para o desenvolvimento de tecnologias e novas abordagens para fomentar a participação das mulheres no contexto da cidade e de suas demandas, no sentido de atualizar o papel da mulher diante da complexidade da sociedade contemporânea. Diante desse cenário, existe um caminho a ser iluminado para dar condições a sociedade de avançar no modo de se relacionar com igualdade e liberdade, trazendo uma nova perspectiva que valorize a experiência de todos e a diversidade.

O entendimento sobre essa questão amplia-se sobre o universo da cidade, apresentando-se como um caminho transversal para aplicação de políticas públicas que buscam atender a diversidade e a melhoria da qualidade de vida da sociedade. Tal fato demonstra que as demandas das mulheres no planejamento urbano não implicam fazer uma cidade especializada unicamente para as mulheres, excluindo o lugar e a demanda dos outros cidadãos, mas sim afirmar uma perspectiva que representa uma nova abordagem de inclusão, do olhar, da opinião, da percepção e da contribuição das mulheres na construção da cidade contemporânea, trazendo assim uma nova dimensão ao desenvolvimento da cidade e da sociedade.

Diante deste contexto, a Carta das Mulheres para a Cidade de Blumenau reuniu e sintetizou a fala dessas mulheres que realizaram o exercício sugerido pela pesquisa que, mesmo sendo uma exploração 
inicial, reflete um recorte da realidade e exprime a percepção dessas mulheres sobre seu direito à cidade. Ao elegerem como temas prioritários a necessidade de mais participação das mulheres no cenário político, segurança pública, mobilidade, rede de equipamentos públicos e habitação, trouxeram luz para esses temas, explorando todas as suas especificidades com o propósito de resolver as questões cotidianas que influenciam suas vidas como usuárias da cidade.

O conteúdo da Carta traz a urgência de se colocar na pauta da construção da cidade contemporânea as demandas relativas às atividades da reprodução, e com isso colocá-las em pé de igualdade como critério para tomada de decisões estratégicas para o desenvolvimento das cidades.

Assim, é possível concluir que a busca pelo exercício pleno da cidadania, tendo como aplicação real o cotidiano da vida das mulheres, pressupõe um caminho de feminilização dos conceitos de Planejamento e das práticas das Políticas Públicas, para que as mulheres possam alcançar o direito de circular com segurança, acessar todos os lugares que desejarem, dispor de equipamentos públicos que atendam as demandas oriundas das atividades com a reprodução, ter espaço para empreendedorismo e participação política e assim, ver diluídos os limites que determinam o vínculo da mulher com o espaço privado, ampliando sua condição de ser parte do espaço público e político da cidade. Uma vez que, com a criação de infraestruturas sociais de apoio às mulheres, atende-se também a família, isso significa avançar no entendimento do planejamento universal e mergulhar nas especificidades dos usuários da cidade. Assim, a provocação que se coloca é a urgência de revisar a dimensão do conceito de "cidadania e democracia", repensando a política "tradicional" universalista marcada pela exclusão dos pobres e pela discriminação sexual. 


\section{Referências}

Arnstein, S. R. (2002). Uma escada da participação cidadã. Revista da Associação Brasileira para o Fortalecimento da Participação - Participe, 2(2), 4-13. Recuperado el 10 de noviembre de 2016, de: http:// aeessp.org.br/escada.pdf.

Calió, S.A. (1991). Relações de gênero na cidade: uma contribuição do pensamento feminista à geografia urbana (Tese de Doutorado). Faculdade de Filosofia, Letras e Ciências Humanas, Universidade de São Paulo, São Paulo, SP, Brasil.

Costa, D. M. (1997). Introdução ao planejamento para o gênero: um guia prático. Rio de Janeiro: IBAM (Textos de Administração Municipal, vol. 14).

Ciocoletto, A. (2014). Espacios para la vida cotidiana. Auditoría de calidad urbana con perspectiva de género. Barcelona: Col.lectiu Punt 6 - Editorial Comanegra. Recuperado el 2 de febrero de 2016, de: http://issuu.com/punt6/docs/espaciosparalavidacotidiana.

Gonzaga, T. O. (2004). A cidade e a arquitetura também mulher: planejamento urbano, projetos arquitetônicos e gênero. São Paulo: Annablume.

Lefebvre, H. (1969). O direito à cidade. São Paulo: Documentos Ltda.

Minayo, M. C.S. (2007). O desafio do Conhecimento: pesquisa qualitativa em saúde (10. ${ }^{\mathrm{a}}$ ed.). São Paulo: HUCITEC (Coleção Saúde em debate, vol. 46).

Montaner, J. M. (2012). Gênero e visão del mundo. En Valdivia, B. G. y Ciocoletto, A. (eds.). Estudios urbanos, gênero y feminismo: Teoria e experiências. Barcelona: ColetiuPunt6, 407-408. Recuperado el 3 de enero de 2017 , de: https://issuu.com/punt6/docs/ publicaciondefinitivaestudiosurbano.
Montaner, J. M. y Muxí, Z. (2014). Arquitetura e Política: Ensaios para mundos alternativos. São Paulo: GG.

Muxí, Z. (2012). Mujeres Públicas. En Valdivia, B.G. y Ciocoletto, A. (eds.) Estudios urbanos, gênero y feminismo: Teoria e experiências. Barcelona: ColetiuPunt6, 445-452. Recuperado el 3 de enero de 2017, de: https://issuu.com/punt6/docs/publicaciondefinitivaestudiosurbano.

Muxí, Z., Casanovas, R., Ciocoletto, A. et al. (2011). ¿Qué aporta la perspectiva de género al urbanismo? Feminismo/s: Revista del Centro de Estudios sobre la Mujer de la Universidad de Alicante, 17, 105-130. Recuperado el 03 de enero de 2017, de: https:// punt6.files.wordpress.com/2011/03/z-muxc3admartc3adnez-r-casanovas-a-ciocoletto-m-fonseca-y-bgutic3a9rrez-valdivia.pdf.

Román, M. y Velázquez, I. (2008). Guía de urbanismo con perspectiva de género. Región de Murcia: Instituto de la Mujer de la Región de Murcia.

Santoro, P.F. (2008). Gênero e planejamento territorial: uma aproximação. En XVI Encontro Nacional de Estudos Populacionais, Caxambu, São Paulo, Brasil, 16. Recuperado el 29 de marzo de 2016, de: http:/ / www.abep.nepo.unicamp.br/encontro2008/docsPDF/ABEP2008_1841.pdf.

Sarmento, D. P. G. (2017). A participação da mulher na construção da cidade contemporânea: contribuições para um novo modelo de planejamento urbano em Blumenau/ $S C$ (Dissertação de Mestrado). Centro de Ciências Humanas e da Comunicação, Universidade Regional de Blumenau, Blumenau, SC, Brasil. Recuperado el 24 de julio de 2018, de: http:/ / www.bc.furb. br/docs/DS/2017/362562_1_1.pdf.

Daniela Pareja Garcia Sarmento, D.P. (2018). Carta das mulheres para a cidade de Blumenau: percepções, demandas e reflexões sobre o direito das mulheres à cidade. Hábitat y Sociedad, 11, 85-107.

<http://dx.doi.org/10.12795/HabitatySociedad.2018.i11.06>

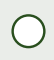




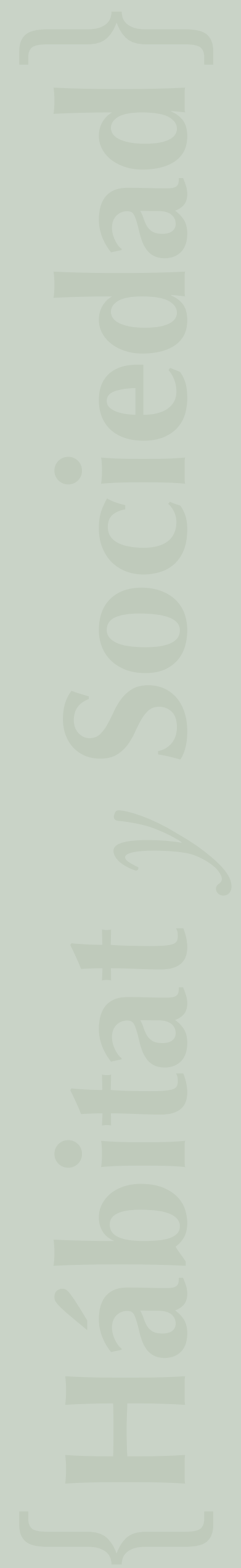

